\title{
Measures of Knee Osteoarthritis: Condition Specific Outcome Measure Scales and their Availability in Bengali Language
}

\author{
Ovijit Baidya ${ }^{*}$, Prosenjit Baidya ${ }^{2}$, Md Abu Talha ${ }^{3}$, Mohammed Zaglul Hai Russeel ${ }^{4}$, Md Monoarul Haque ${ }^{5}$, \\ Naym Uddin Roby ${ }^{6}$ and Md Anowarul Islam ${ }^{7}$ \\ ${ }^{1,2}$ MPT (Orthopaedics), Lovely Professional University, India \\ ${ }^{3}$ MPhil (Fellow), Institute of Environmental Science, University of Rajshahi, Bangladesh \\ ${ }^{4}$ Consultant Physiotherapist, Uttara Crescent Hospital, Bangladesh
}

${ }^{5}$ Publication Secretary, Bangladesh Physical Therapy Association (BPA)

${ }^{6}$ National Field Experience Trainee, ICDDRB

${ }^{7}$ Physiotherapist, Bosundhara Physiotherapy and Rehabilitation Center, Dhaka

Submission: February 07, 2018; Published: March 06, 2018

*Corresponding author: Ovijit Baidya, MPT (Orthopaedics), Lovely Professional University, Punjab, India, Email: gpabd17@gmail.com

\begin{abstract}
Billions of people around the world are affecting from various joint diseases among which osteoarthritis is one of the most common condition. Osteoarthritis (OA) affects a patient's quality of life and have significant impact on individuals and on the society as well. For evaluation of patient's condition with OA, patient reported outcome measures (PROs) are a useful measure which is widely used in clinical settings. This review focuses on the validity, reliability of seven scales that are used for evaluation of knee osteoarthritis and availability of these scales Bengali translated version for using in Bangladeshi population. From the seven English version scales only four scales (WOMAC, KOOS, SF-36 and SF-12) are having Bengali translated version. Among which only three (WOMAC, SF-36 and SF-12) scales are proved to be reliable and valid for general use. But a matter of fact that among the Bengali translated versions only SF-12 Bengali version is easily available in the internet for regular use but it lacks in measuring the pain intensity of patient. So, Bengali translation of other new outcome measures like ICOAP, KOOS-PS should be done and already translated and validated versions should be made available for public use.
\end{abstract}

\section{Introduction}

Osteoarthritis is the most common degenerative and noninflammatory joint disease and a major cause of disability affecting the elderly patients $[1,2]$. Involvement of the knee joint is the most common feature of this disease throughout the world and is an important cause of pain [2,3]. The estimated prevalence of knee osteoarthritis in general population of Bangladesh is $7.3 \%$ and slightly high among ethnic communities which is $10.4 \%$ [4,5]. 30-64 years age group are most commonly affected and female are mostly prone to osteoarthritis [6]. As knee and hip osteoarthritis increases as a result of the aging of the population, the disorder becomes a serious threat to the general health [7]. So, it is essential to optimize treatment and evaluate the interventions that might prevent or delay the progression of the condition [2]. The evaluation of patient's condition suffering from knee osteoarthritis can be done using different outcome measure tools or scales. At present there are several condition specific instruments available for evaluation of specific knee OA. They are Western Ontario and McMaster
Universities Osteoarthritis Index (WOMAC), Intermittent and Constant Osteoarthritis Pain measure (ICOAP), Knee Injury and Osteoarthritis Outcome Score (KOOS), Knee Disability and Osteoarthritis Outcome Score Physical Function Short Form (KOOS-PS), Lysholm Knee Scale, Generic health status questionnaires Short Form-36 (SF-36) and Short form SF 12 [8-11]. In this review the psychometric properties of the knee OA outcome measures were discussed and availability of these scales for using in Bangladeshi population was explored.

\section{Methodology}

This review was conducted in two steps. First step was to review the outcome measure scales available for knee osteoarthritis. A literature search on Google Scholar was done during the first week of January 2018. The keyword for search was "(Outcome OR Measure OR Measures OR scale OR scales) AND (of OR for) AND knee AND (osteoarthritis OR OA OR injury OR pain)". The initial total number of selected articles was 25 . After removing the similar articles, the count was reduced to 23 
articles. Title and abstract and conclusions of each article were read to identify and exclude non- related studies. Articles which were not published in English language were removed. After this selection, the count was reduced to 14 articles. Different library searches and request for the full text of these articles were conducted. The total number of the articles for which the full text was retrieved was 14. After reviewing the selected articles, a list of scale was done on which further review was conducted. Second step of the review was on the selected scales found after the first step. A literature search on Google Scholar was done using the title of the scale to find out the reliability and validity of those English version scales. Then a literature search on Google and Official website of those scales were done to find out the availability of those scales in Bengali language and their psychometric properties. The scales which were found in this step were considered as "easily available" rest of the scales were considered "not easily available". To get additional information on these "not easily available" scales, mail was sent to the original author.

\section{The WOMAC Index}

The WOMAC is a condition specific self-reported questionnaire. The scale includes five questions asking pain at activity or rest, two questions measuring stiffness and 17 questions exploring the degree of difficulty during activities. The original WOMAC is present in both visual analogue scales (VAS) and five Likert boxes format [8]. The scale was developed in 1982 and the latest modified version is available in over hundred languages [12]. The WOMAC 3.1 has been validated and is widely used in the evaluation of knee and hip osteoarthritis. In several studies disease specific questionnaire WOMAC showed high validity. The questionnaire was also reproducible over time. Responsiveness tended to be higher in women and in knee OA than in men and hip OA [13]. Bengali version of WOMAC 3.1 was developed in 2014 and was found valid for assessing quality of life of patients with knee OA in Bangladeshi population. Reliability testing using Cronbach's alpha and ICC values was found more than 0.7 in all the domains indicating WOMAC Bangla version is having satisfactory reliability. The Bengali translated version has shown similar construct validity as HAQ ( $\rho$ 0.74). Spearman's rank correlation coefficient between WOMAC pain with Short From-36 bodily pain and physical functioning was found -0.67 and -0.68 respectively indicating good negative correlation between the scales [14].

\section{The Intermittent and Constant Osteoarthritis Pain (ICOAP)}

The Intermittent and Constant Osteoarthritis Pain (ICOAP) Score is an eleven item scale specifically made for assessment of hip or knee OA pain. ICOAP scale comprise two subscales considering both pain intensity and the effect of pain on daily life, where five questions scale evaluates patients constant pain and six questions evaluates patients intermittent pain. The latest available version of the ICOAP is version 3 , which was developed in 2007. In a hip or knee OA around 40+ year's age, ICOAP was found to be internally consistent and reliable $[15,16]$. ICOAP scale is available in several languages which are valid too, but still there is no Bengali version of the ICOAP scales available (Table 1 \& 2).

Table 1: Overview of Knee OA pain measuring Scale available in Bengali.

\begin{tabular}{|c|c|c|c|c|c|c|c|}
\hline Name of Scale & Version & Author & Year & Area of study & Reliability & Validity & $\begin{array}{c}\text { Easily } \\
\text { Available in } \\
\text { Internet }\end{array}$ \\
\hline $\begin{array}{l}\text { Bengali version } \\
\text { of WOMAC }\end{array}$ & VA 3.01 & $\begin{array}{c}\text { Rabbani MG et } \\
\text { al. [14] }\end{array}$ & 2014 & $\begin{array}{l}\text { BSMMU*, } \\
\text { Dhaka }\end{array}$ & Reliable & Valid & Not available \\
\hline $\begin{array}{l}\text { KOOS Bengali } \\
\text { version }\end{array}$ & LK 1.0 & $\begin{array}{c}\text { Karvannan H et } \\
\text { al. [19] }\end{array}$ & 2013 & India & $\begin{array}{l}\text { No study has } \\
\text { been done }\end{array}$ & $\begin{array}{l}\text { No study has } \\
\text { been done }\end{array}$ & Available \\
\hline $\begin{array}{l}\text { Bengali Short } \\
\text { Form-36 }\end{array}$ & Ver1 & $\begin{array}{c}\text { Feroz AH et al. } \\
{[22]}\end{array}$ & 2012 & $\begin{array}{l}\text { BSMMU*, } \\
\text { Dhaka }\end{array}$ & Reliable & Valid & Not available \\
\hline $\begin{array}{l}\text { Bengali Short } \\
\text { Form SF } 12\end{array}$ & Ver2 & $\begin{array}{c}\text { Islam } \mathrm{N} \text { et al. } \\
{[9]}\end{array}$ & 2017 & $\begin{array}{c}\text { BSMMU*, } \\
\text { Dhaka }\end{array}$ & Reliable & Valid & Available \\
\hline
\end{tabular}

*BSMMU= Bangabandhu Sheikh Mujib Medical University. 
Table 2: Flow chart showing the status of availability of Bengali translated Knee OA scales.

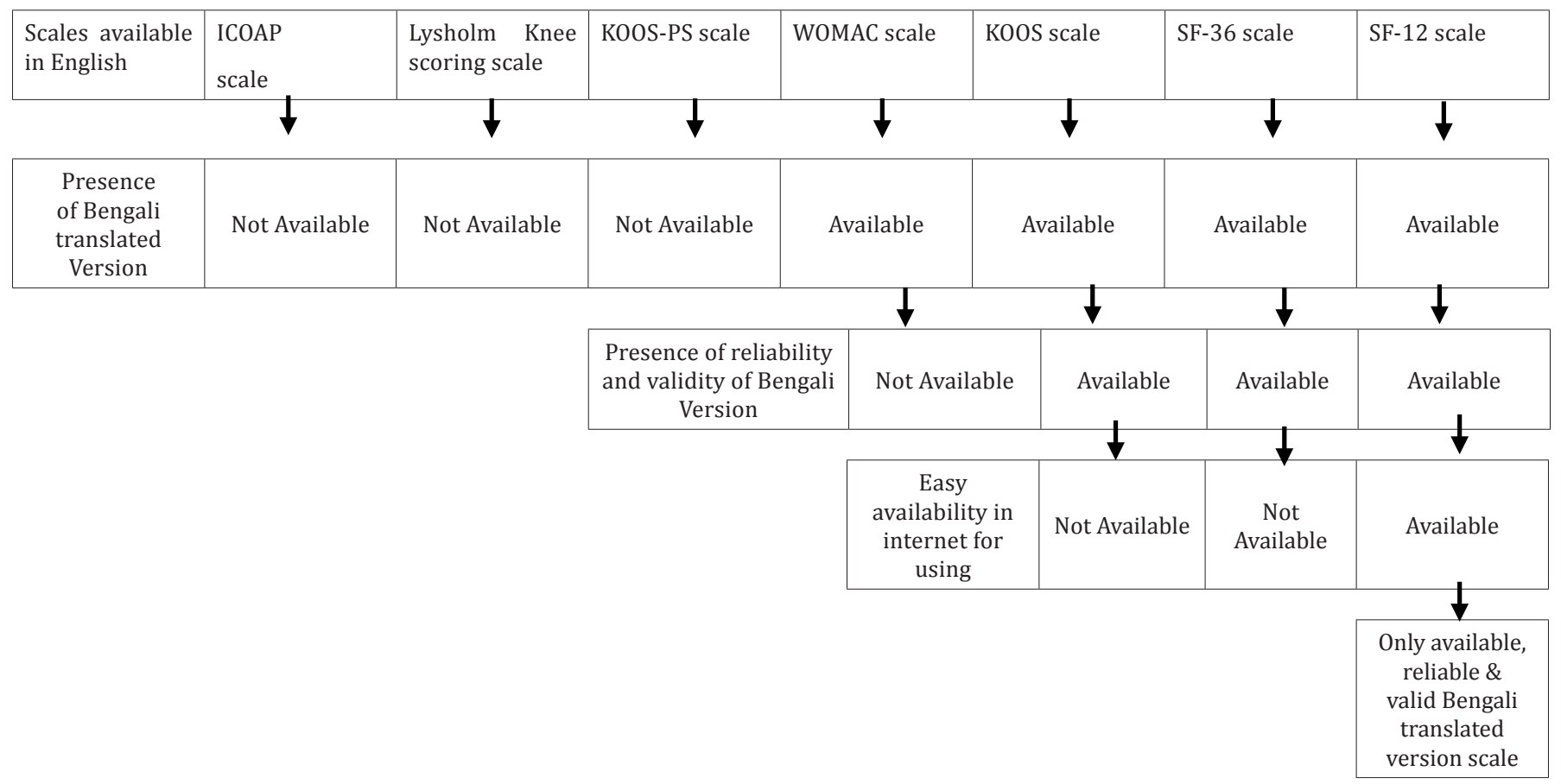

\section{Knee Injury and Osteoarthritis Outcome Score}

KOOS scale is a condition specific scale to measure patient's condition in osteoarthritis (OA) which can be primary OA or results of a trauma or injury. KOOS assess total five components including pain, symptoms, daily function, sport or recreational function and quality of life. High reliability, validity and responsiveness of KOOS scale after surgical procedures (like ACL reconstruction, meniscectomy, knee replacement surgery) and physical therapy intervention has been reported in several studies $[17,18]$. KOOS version LK1.0 is available in the original English and many other languages of the world. KOOS Bengali version LK 1.0 is also available which was developed in November 2013 by H Karvannan et al. [19] In that study the original English version was translated and adapted in Bengali language for measuring patients condition treated with total knee replacement following knee osteoarthritis. However, no validity or reliability study has been done on the Bengali version of KOOS LK1.0.

\section{Knee Disability and Osteoarthritis Outcome Score Physical Function Short Form (KOOS-PS)}

The KOOS-PS is a seven questions scale derived from the subscales of the KOOS. It is a recommended tool for measuring physical functional of patients with knee injuries and knee $\mathrm{OA}$ to follow the progression of disability and to evaluate treatment responses. Several studies have demonstrated the responsiveness, validity and reliability of KOOS-PS in knee osteoarthritis patents [20]. Although it is available and validated in several languages but Bengali version of KOOS-PS is still not developed.

\section{Short Form-36 (SF-36)}

The Medical Outcomes Study 36-Item Short Form or SF-36 is widely accepted and commonly used general health outcomes measure. The SF-36 consists of eight subscales containing total 36 questions and one general overall health status question. The SF-36 is available in several languages which are valid too. The advantage of this health outcomes measure is that it can be used to compare across different diseases and conditions [8]. First version of Short Form 36 was developed in 1992 [21]. The Bengali Short Form-36 was developed on May 2012 by Abu HM Feroz et al. [22] was found to be reliable and valid for using in Bangladeshi patients with RA. Cronbach's alpha of the Bengali SF -36 version was higher than 0.78 and the test retest reliability was high $(r>0.82)$ for all scales. The high correlations of this scale with other disease parameters established the validity of the Bengali translated version of SF-36.

\section{Short Form-12 (SF-12)}

The SF-12 is a short version of SF-36 questionnaire made to provide a short and valid substitute to the SF-36. The questions of this scale are divided into two sections to separately assess the physical as well as the mental component of health [23]. The SF-12 was developed in 1996 [24] and it was culturally adapted and validated into Bengali language in 2017 by Islam $\mathrm{N}$ et al. [9] Patients acceptancy was high for the Bengali translated version. Internal consistency for both physical and mental component of the scale is satisfactory with a Cronbach's alpha value of 0.9 and ICC value more than 0.9 indicating reliability of the Bengali version scale. At the same time convergent and discriminant validity of the Bengali SF-12 and Bengali HAQ scale was acceptable. 


\section{Orthopedics and Rheumatology Open Access Journal}

\section{Lysholm Knee Scoring Scale}

Lysholm Knee Score is the scoring systems made specially to use in ACL injuries and chondral defects. It was published in 1982. The current modified and revised version of Lysholm was introduced in 1985 which analyse patient's condition on eight segments: pain, instability, locking, swelling, limp, stair climbing, squatting and need for support. The overall Lysholm score has acceptable test-retest reliability (ICC $=0.91$ ), internal consistency (Cronbach alpha=0.65) and construct validity [25]. Although it is available and validated in several languages but Bengali version of Lysholm Knee Scoring Scale is still not developed.

\section{Discussion}

All the scales (WOMAC, ICOAP, KOOS, KOOS-PS, SF-36, SF-12 and Lysholm scale) reviewed in this study are having satisfactory reliability and validity for the original English version $[8,13,15,20]$. Among which 4 scales (WOMAC, KOOS, SF-36 and SF-12) are having Bengali translated version and all the translated versions except KOOS are found reliable and valid $[9,14,20,22]$. But a matter of fact that Bengali version of WOMAC and SF-36 are not easily available in the internet for regular use. Only the SF-12 Bengali version is easily available in the internet, but the main weakness of the scale is that this scale only access patient's physical and mental health in spite of the pain intensity [9].

\section{Conclusion}

Bengali translation of other new outcome measures like ICOAP, KOOS-PS should be done. Already translated versions should be made available for public use and further evaluated in general population and in patients treated with different interventions.

\section{Limitations}

This review was conducted within a limited time period and there was no additional funding to support this review. That's why wide and systemic literature search was not performed and the review was done on the limited articles attainable.

\section{References}

1. Lohmander LS (2000) What can we do about osteoarthritis? Arthritis Research \& Therapy 2(2): 95-100.

2. Maillefert JF, Kloppenburg M, Fernandes L, Punzi L, Günther KP, et al. (2009) Multi-language translation and cross-cultural adaptation of the OARSI/OMERACT measure of intermittent and constant osteoarthritis pain (ICOAP). Osteoarthritis and Cartilage 17(10): 1293-1296.

3. Fukutani N, Iijima H, Fukumoto T, Uritani D, Kaneda E, et al. (2016) Association of varus thrust with pain and stiffness and activities of daily living in patients with medial knee osteoarthritis. Physical Therapy 96(2): 167-175.

4. Ahmed S, Haq SA, Al-qadir AZ, Rahman MM, Paul S (2017) SAT0713 Survey on prevalence of rheumatic disorders in Bangladeshi adults. Annals of the Rheumatic Diseases 76(2): 1044-1045.

5. Abu Sadath MM Islam, Belayet H Akanda, Bakhtiar, Md Monoarul Haque, Ropak Chandra Roy, et al. (2016) Prevalence of osteoarthritis among ethnic communities in Bangladesh. EC Orthopaedics 3: 284289.

6. Jahan I, Haque S, Khalil M, Sohel MD, Kawsar MH (2017) Survey on prevalence, risk factors and treatment pattern of osteoarthritis in bangladesh: retrospective study. Rheumatology 7(4): 1-6.

7. Das SK, Farooqi A (2008) Osteoarthritis. Best Pract Res Clin Rheumatol 22(4): 657-675.

8. Wright RW (2009) Knee injury outcomes measures. J Am Acad Orthop Surg 17(1): 31-39.

9. Islam N, Khan IH, Ferdous N, Rasker JJ (2017) Translation, cultural adaptation and validation of the English "Short form SF 12v2" into Bengali in rheumatoid arthritis patients. Health Qual Life Outcomes 15(1): 109.

10. Collins NJ, Misra D, Felson DT, Crossley KM, Roos EM (2011) Measures of knee function: International Knee Documentation Committee (IKDC) Subjective Knee Evaluation Form, Knee Injury and Osteoarthritis Outcome Score (KOOS), Knee Injury and Osteoarthritis Outcome Score Physical Function Short Form (KOOS-PS), Knee Outcome Survey Activities of Daily Living Scale (KOS-ADL), Lysholm Knee Scoring Scale, Oxford Knee Score (OKS), Western Ontario and McMaster Universities Osteoarthritis Index (WOMAC), Activity Rating Scale (ARS), and Tegner Activity Score (TAS). Arthritis Care Res 63(11): 208-228.

11. Goncalves RS, Meireles AC, Gil JN, Cavalheiro LM, Rosado JO, et al (2012) Responsiveness of intermittent and constant osteoarthritis pain (ICOAP) after physical therapy for knee osteoarthritis. Osteoarthritis Cartilage 20(10): 1116-1119.

12. Bellamy N (2016) Womac Osteoarthritis Index, USA.

13. Salaffi F, Leardini G, Canesi B, Mannoni A, Fioravanti A, et al. (2003) Reliability and validity of the Western Ontario and McMaster Universities (WOMAC) Osteoarthritis Index in Italian patients with osteoarthritis of the knee. Osteoarthritis Cartilage 11(8): 551-560.

14. Rabbani MG, Haq SA, Bellamy N, Islam MN, Choudhury MR, et al. (2015) Development, linguistic and clinimetric validation of the WOMAC ${ }^{8}$ VA3. 01 Bangla for Bangladesh Index. Rheumatol Int 35(6): 997-1003.

15. Bond M, Davis A, Lohmander S, Hawker G (2012) Responsiveness of the OARSI-OMERACT osteoarthritis pain and function measures. Osteoarthritis Cartilage 20(6): 541-547.

16. Hawker GA, French MR, Davis AM, Dieppe P (2008) Further validation of OARSI-OMERACT intermittent and constant osteoarthritis pain (ICOAP) measure. Osteoarthritis and Cartilage 16(4): S203

17. Koosnu (2018) What is the KOOS?

18. Roos EM, Roos HP, Lohmander LS, Ekdahl C, Beynnon BD (1998) Knee Injury and Osteoarthritis Outcome Score (KOOS)-development of a self-administered outcome measure. Journal of Orthopaedic \& Sports Physical Therapy 28(2): 88-96.

19. Karvannan H, Chakravarty RD, Arun G Maiya, Naomi Simick (2013) Bengali Knee injury and Osteoarthritis Outcome Score (KOOS), Koosnu.

20. Ruyssen-Witrand A, Fernandez-Lopez CJ, Gossec L, Anract P, Courpied JP, et al. (2011) Psychometric properties of the OARSI/OMERACT osteoarthritis pain and functional impairment scales: ICOAP, KOOSPS and HOOS-PS. Clinical and Experimental Rheumatology-Incl Supplements 29(2): 231-237.

21. Brazier JE, Harper R, Jones NM, O'cathain A, Thomas KJ, et al. (1992) Validating the SF-36 health survey questionnaire: new outcome measure for primary care. BMJ 305(6846): 160-164.

22. Feroz AH, Islam MN, ten Klooster PM, Hasan M, Rasker JJ, et al. (2012) The Bengali Short Form-36 was acceptable, reliable, and valid in patients with rheumatoid arthritis. J Clin Epidemiol 65(11): 12271135. 
23. Utah Health Status Survey (2001) Interpreting the SF-12. Utah Department of Health, utah.gov.

24. Ware Jr JE, Kosinski M, Keller SD (1996) A 12-Item Short-Form Health Survey: construction of scales and preliminary tests of reliability and validity. Medical care 34(3): 220-233.
25. Kocher MS, Steadman JR, Briggs KK, Sterett WI, Hawkins RJ (2004) Reliability, validity, and responsiveness of the Lysholm knee scale for various chondral disorders of the knee. J Bone Joint Surg Am 86(6): 1139-1145.

\section{Your next submission with Juniper Publishers} will reach you the below assets

- Quality Editorial service

- Swift Peer Review

- Reprints availability

- E-prints Service

- Manuscript Podcast for convenient understanding

- Global attainment for your research

- Manuscript accessibility in different formats ( Pdf, E-pub, Full Text, Audio)

- Unceasing customer service

Track the below URL for one-step submission https://juniperpublishers.com/online-submission.php 